\title{
CURITIBA - 50 ANOS DE ELEIÇÕES MUNICIPAIS - AS FORÇAS POLÍTICAS QUE NAS DEMOCRACIAS E NO GOVERNO DISPUTAM O PODER, de Mauro Pioli Rehbein ${ }^{1}$
}

Katiano Miguel Cruz ${ }^{2}$

- Enviado em 27/01/2016

- Aprovado em 24/02/2016

A dissertação de mestrado Curitiba - 50 anos de eleições municipais - as forças políticas que nas democracias e no governo militar disputam o poder, do autor Mauro Pioli Rehbein, investiga em profundidade as eleições municipais realizadas em Curitiba, para prefeito e Câmara Municipal de vereadores, no período de 1947 a 2004. O objeto de estudo desta pesquisa, que enfatiza os processos eleitorais majoritários e proporcionais de Curitiba, circunda entre quatro fatores principais, que são: os sistemas eleitorais vigentes nas três formas de governo dos períodos investigados (redemocratização, regime militar e nova redemocratização), com suas regras eleitorais; os atores políticos, que são os partidos e os candidatos; as eleições e seus resultados; e, por último, a análise dos eleitores curitibanos e seu comportamento eleitoral.

Não está entre as finalidades do estudo a análise sobre democracia e ditadura no Paraná, mas sim o processo eleitoral em si e sua evolução. Interessante frisar que, como o trabalho segue uma estrutura em forma de "linha do tempo", é possível acompanhar de certa forma a evolução do Código Eleitoral Brasileiro, necessário para entender as especificidades dos períodos. Assim, foram elencados vários elementos pertinentes da história política brasileira. Numa leitura atenta do

\footnotetext{
${ }^{1}$ Dissertação de autoria de Mauro Pioli Rehbein, defendida no Programa de Pós-Graduação em Sociologia da UFPR, em 2008, sob orientação do Prof. Dr. Ricardo Costa de Oliveira. Versão completa disponível na Biblioteca Digital da UFPR-

http://dspace.c3sl.ufpr.br:8080/dspace/bitstream/handle/1884/25274/REHBEIN\%2c\%20MAURO\%20PIOLI\%20\%28C orreto\%29.pdf?sequence $=1 \&$ is Allowed $=y$

${ }^{2}$ Graduado em Administração pela Pontifícia Universidade Católica do Paraná, Especialista em Sociologia Política pela Universidade Federal do Paraná. Endereço eletrônico: katianomc@ yahoo.com.br
} 
trabalho, o leitor adquire também uma compreensão do quadro geral do cenário institucional brasileiro, podendo inclusive partir daí para estudos mais aprofundados.

A dissertação é dividida em três partes: a primeira parte trata da quarta república, do período de 1945 a 1964, a redemocratização após o Estado Novo; a segunda parte trata da quinta república, do período de 1964 a 1985, o regime militar; e por último, a terceira parte, apresenta a sexta república, de 1985 até 2004, com a nova redemocratização.

Um trabalho estritamente teórico, que se utilizou de fontes primárias, tais como jornais paranaenses e arquivos do TRE, como também de livros e obras acadêmicas, da área de Sociologia Política e Ciência Política, que tratam sobre o objeto e seus fatores diretos. Destes últimos, destacam-se as obras que tratam dos partidos políticos, do espectro ideológico, obras que tratam de eleições municipais, do sistema eleitoral brasileiro, referentes aos períodos investigados, e também sobre a política paranaense, além de trabalhos sobre comportamento eleitoral no Brasil ${ }^{3}$. O trabalho em si não possui um capítulo propriamente dito que explique a metodologia utilizada para comprovação das hipóteses, mas foi com base nas informações e números levantados nas fontes primárias, e utilizando da conceituação teórica levantada na bibliografia, que o autor apresenta suas conclusões parciais e finais, como um estudo comparado. Como ele mesmo afirma, "os métodos aplicados nesses estudos para avaliação das eleições não foram até então empregados nos estudos e investigações das eleições no Brasil, [...] [portanto] o objetivo aqui é adotar novas formas de avaliar e enriquecer a avaliação da sociologia eleitoral brasileira” (p. 32).

A primeira parte do trabalho trata da Quarta República, no período de 1945 a 1964, ou seja, da redemocratização após o Estado novo. Nesta, são analisadas, com detalhes, as eleições proporcionais para a Câmara de vereadores (1947, 1951, 1955, 1959 e 1963) e as eleições majoritárias para prefeito, sendo a primeira em 1954, seguida pelos pleitos de 1958 e 1962 . Para

\footnotetext{
${ }^{3}$ Listo aqui as principais obras utilizadas para análise comparativa do trabalho: Estado e partidos políticos no Brasil (1939 a 1964), de Maria do Carmo Campello de Souza (1990); Oposição e autoritarismo: gênese e trajetória do MDB (1966-1979), de Maria D’Alva Kinzo (1988); Partidos, ideologia e composição social, de Leôncio Martins Rodrigues (2002); A sociologia dos partidos políticos, de Robert Michels (1982); "Da Distensão a Abertura - As Eleições de 1982" (1988) e "Manipulações casuísticas do sistema eleitoral durante o período militar, ou como usualmente o feitiço se volta contra o feiticeiro" (1994), de David Verge Fleischer; "O Voto no Brasil - Da Colonia a sexta Republica" (2002), de Walter Costa Porto; "História do Voto no Brasil" (2002) e "Sistema Eleitoral" (2004), de Jairo Nicolau; "A Legislação Eleitoral Brasileira" (1964), de Edgar Costa; "Partidos Políticos no Brasil (1945-2000)" (2000), de Rogério Schmitt; "Partidos Políticos Brasileiros 45 a 64" (1983), Olavo Brasil de Lima Jr.; "O Silencio dos Vencedores Genealogia, Classe Dominante e Estado no Paraná" (2001) e "A Construção do Paraná Moderno - Políticos e Políticas no Governo do Paraná de 1930 a 1980" (2004), de Ricardo Costa Oliveira; "Por dentro do MDB - Paraná" (1992), de Sylvio Sebastiani; "Memorias de 1964 no Paraná" (2000), de Milton Ivan Heller e Maria L. A. Dulce; "Paraná político de cabo a rabo" (1999), de Pedro Washington de Almeida; "Esquerda e Direita no Eleitorado Brasileiro" (1999), de André Singer; "A Decisão do Voto nas Eleições Presidenciais Brasileiras", (2002), de Yan de Souza Carreirão; e, "Comportamiento Político, Partidos y Grupos de Presion - Sociologia Electoral" (2003), de Irene D. Sotillos e Lourdes Lopez Nieto.
} 
cada pleito, divido por tópicos no capítulo, é apresentada uma contextualização com o cenário político estadual e nacional, e também bases de dados completa, com nomes, partidos, número de votos (por zonas eleitorais inclusive, apresentando mapas de Curitiba), estatísticas comparativas, dentre outras informações, sendo uma fonte extremamente rica para consulta, incluindo ainda hipóteses sobre o tipo do voto do curitibano.

No começo do capítulo, o autor discorre sobre o período antecedente ao analisado, apontando as forças políticas da República Velha e do Estado Novo, traçando a descontinuidade que viria com a eleição de Ney Braga em 1954. As duas principais forças políticas que dominavam o governo estadual antes da Quarta República eram representadas, em primeiro, pelas famílias Camargo e Munhoz da Rocha, que governaram praticamente durante toda a República Velha, sendo afastadas do poder com a Revolução de 30 e a Interventoria de 32 (porém, voltando ao governo com Bento Munhoz da Rocha Neto em 1951), sendo o outro grupo representado por Manoel Ribas, interventor indicado por Getúlio Vargas, que se manteve no poder durante todo o Estado Novo e tendo Moyses Lupion como herdeiro de seu legado político.

Com a nova constituição promulgada em 1946, as datas das eleições foram definidas. Antes da Constituição, os prefeitos eram nomeados, no entanto, mesmo depois da promulgação desta, continuaram as nomeações em razão do estabelecido, referente as eleições municipais, na Carta Magna do Paraná de julho de 1947 (isso até o primeiro pleito em 1954). O sistema eleitoral era de maioria simples, assim, os três prefeitos eleitos na época não representavam a maioria da população (Ney Braga em 54, teve apenas 29,96\% dos votos válidos, por exemplo).

Conclui-se que no período, os partidos de maior representatividade foram: em primeiro o PTB, que teve 27 vereadores eleitos, em segundo o PSD de Moyses Lupion, com 18 cadeiras, e em terceiro empatados com 12 cadeiras, a UDN e o PR. Apenas o PTB conseguiu eleger prefeito sem coligação (Iberê de Mattos em 1958). Ney Braga aparece como o maior nome da política paranaense no período, sendo prefeito, deputado e governador, inclusive emplacando seu candidato a prefeito no último pleito antes do regime militar, Ivo Arzua.

Na segunda parte, que discorre sobre a Quinta República, ou regime militar (de 1964 a 1985), o autor comenta as alterações do sistema eleitoral advindas com o golpe, os meandres políticos, suspensão da constituição, os Atos institucionais, o bipartidarismo, etc. O governador, que passou a ser indicado pelo presidente, era quem indicava o candidato a prefeito, sendo este referendado pelos deputados estaduais e, uma vez aprovado, nomeado para assumir o cargo. Neste período foram seis indicações, seguidas dos referendos e nomeações, sendo os cinco primeiros representantes da ARENA, dominando assim praticamente todo o período do regime militar. Foi aí 
que surgiu o nome Jaime Lerner, prefeito em 1971 (nomeado por Haroldo Leon Peres) e 1979 (nomeado por Ney Braga), despontando como um dos principais (se não o principal) políticos paranaenses. Apenas o último prefeito nomeado, Maurício Fruet, era do PMDB (nova sigla do MDB), indicado pelo Governador eleito por voto direto em 1982, José Richa. Os outros prefeitos foram Ivo Arzua em 1966, Omar Sabbag em 1967 e Saul Raiz em 1975.

Nos tópicos sobre os referendos, o autor apresenta com detalhes quadros com as votações dos deputados, analisando principalmente a estratégia do MDB do Paraná, com sua oposição consentida. Ney Braga aparece como o grande articulador político do regime militar no Paraná.

Em relação às eleições proporcionais para Câmara de Vereadores neste período, o autor analisa somente aquelas que foram disputadas sob vigência do bipartidarismo, entre ARENA e MDB, deixando a análise da conseguinte para a parte da redemocratização (terceira parte), uma vez que voltava o pluripartidarismo. Nesse contexto foram apenas três, em 1968, 1972 e 1976. Indiscutivelmente a ARENA foi majoritária nos três pleitos, tanto no número de cadeiras como no de votos válidos. Foram quarenta e um candidatos eleitos nas três eleições, contra vinte e dois do MDB. Assim como na primeira parte, o autor apresenta os quadros com os dados estatísticos e todas as informações em relação aos pleitos. Importante frisar que, mesmo analisando somente esses três pleitos, denota-se que a ARENA começa a declinar em 1974, tanto nas bancadas da Assembleia Legislativa e da Câmara Federal, o que já impactou o terceiro pleito e atingindo sua decadência na eleição proporcional de 1982, quando fica com metade das cadeiras (já como PDS).

E por último, na terceira parte que discorre sobre a Sexta República, ou a nova redemocratização, iniciada em 1985 com a abertura política do regime militar, o autor mais uma vez inicia com uma apresentação do cenário nacional, com o primeiro presidente civil, a constituição de 1988, depois Collor e o impeachment, a eleição de Fernando Henrique Cardoso e as alterações no código eleitoral, que passou a permitir as reeleições em todos as esferas, e por último a ascensão do PT, em 2002. No governo do estado, é apresentada a polarização política pelos grupos formados pelo PMDB, que passaria a ser representado por Requião, e o grupo de Lerner, além de seus inúmeros embates, que já começara com a disputa de prefeito em 1985.

Em relação aos pleitos para prefeito, o autor analisa que a abertura política, em 1985, começa com um pedido de mudança do povo curitibano, ao eleger o candidato peemedebista Roberto Requião, que disputava contra Jaime Lerner, que ainda representava aquela imagem do grupo que dominou o período do regime militar. Todavia, a eleição majoritária de 1988, foi o início da hegemonia do grupo de Lerner e seus sucessores políticos. Na sequência foram, Lerner (1988), Greca (1992), Cassio Taniguchi (1996 e 2000) e Beto Richa (2004 e 2008), ao todo 20 anos à frente 
do poder municipal. Apesar dessa hegemonia não ser apenas de um partido propriamente dito, é sim de um grupo político, que transitaram entre as legendas de partidos conservadores, de centro e de direita.

Importante frisar que essa parte do trabalho já conta também com dados das pesquisas de intenção de voto, assim é possível traçar a evolução dessa intenção de voto para cada candidato à prefeitura, comparando-as aos números finais.

Em relação às eleições proporcionais do período, foram analisados os pleitos de 1982, 1988 (esta já acontecendo em simultâneo às eleições majoritárias), 1992, 1996, 2000 e 2004. Tal como nas eleições majoritárias, o primeiro pleito para Câmara Municipal foi dominado pelo PMDB, que obteve o dobro de cadeiras do PDS, reafirmando o "pedido de mudança". Após 1988, com o pluripartidarismo revigorado, a fragmentação partidária da câmara já começa a ser percebida, o que só aumenta com o passar dos pleitos, bem como o declínio do PMDB. Um fenômeno perceptível também, em relação aos dois últimos pleitos analisados, foi o crescimento dos partidos de esquerda, liderados principalmente pelo PT. Tal como nas duas primeiras partes do trabalho, o autor apresenta as listas dos candidatos eleitos, com todos os detalhes da eleição.

A análise das reeleições da Câmara Municipal se tornou um tanto complexa a partir desse período, pois as migrações partidárias foram constantes. A prevalência das migrações, com relação ao espectro ideológico, é de direita para direita, e mesmo com todo o vai e vem, as reeleições chegam a atingir índices de até $60 \%$ da bancada total. O que reafirma uma das hipóteses do autor, baseado na bibliografia da área, de que o voto do curitibano é extremamente personalista e de continuidade.

$\mathrm{O}$ autor considera obviamente, entre as hipóteses iniciais e conclusões, o crescimento do eleitorado e das seções eleitorais ocorridas nos períodos. Em 1954 havia um eleitorado de 97.240, no final da Quarta República já haviam 144.571, quando da reabertura em 1985 eram 624.303, e na última eleição investigada, em 2004, o eleitorado já contava com 1.179.223. Os mapas ilustrativos das seções eleitorais e seus respectivos percentuais de votos, apresentam as características das bases de voto de cada grupo político e/ou partido. A apresentação de cada tópico, sendo que cada um se refere a um pleito específico, é bem detalhada e devidamente contextualizada, o que impede que o leitor se perca nesse percurso histórico recheado de siglas, datas e legislações. Um trabalho de extremo fôlego e muito rico em informações, praticamente uma enciclopédia, uma compilação completíssima de atores políticos, parentescos, partidos e sua evolução, processos políticos, dados e estatísticas, e até da cultura política da história de Curitiba. Entender historicamente o que 
representa a trajetória de um político ou partido é fundamental para qualquer pesquisador da área, e nesse sentido, este trabalho acadêmico se torna um achado valiosíssimo. 